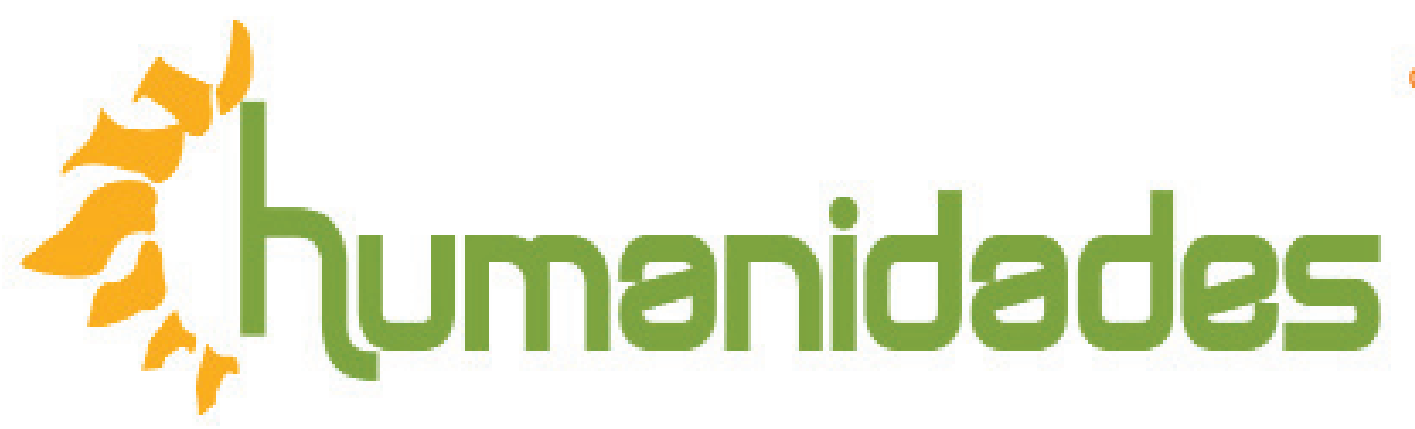

Revista de la Escuela de Estudios Generales, Universidad de Costa Rica

Enero-julio, 2019 •Volumen 9, número 1 • EISSN 2215-3934 • pp. 1-29

Recibido: 17-Abril-2018 Aceptado: 27-Mayo-2018

\title{
El lugar de la insistencia: una aproximación a los prefacios alógrafos de Edwidge Danticat
}

DOI: https://doi.org/10.15517/h.v9i1.35284

\section{Jaime Morales Quant}

Doctorando en Literatura. Universidad de Buenos Aires, Argentina.

Correo electrónico: jamoq22@hotmail.com

Todos los derechos reservados. Universidad de Costa Rica. Esta revista se encuentra licenciada con Creative Commons. Reconocimiento-NoComercial-SinObraDerivada 3.0 Costa Rica. Correo electrónico: humanidades@ucr.ac.cr/ Sitio web: http: //revistas.ucr.ac.cr/index.php/ humanidades 


\section{El lugar de la insistencia: una aproximación a los prefacios alógrafos de Edwidge Danticat}

\section{Resumen}

En el siguiente ensayo, abordo una dimensión de la obra de Edwidge Danticat que no ha sido estudiada sistemáticamente: la configuración de sus prólogos alógrafos. Me interesa aproximarme a las introducciones de The Butterfly's Way: Voices from the Haitian Dyaspora in the United States, Haiti Noir y Haiti Noir 2, entendiéndolas como espacios de la repetición. Y, en este sentido, defiendo dos hipótesis centrales: 1) a través de los prefacios, Danticat reitera un tópico fundamental que ya es visible en sus primeras producciones narrativas. Me refiero a las manifestaciones de la vida precaria o vulnerable en Haití, es decir, a las formas en las que un ser humano se encuentra expuesto a otro, bajo las fuerzas de la opresión o del afecto (Butler, 2006, 2010). Desde una posición crítica, la escritora examina prácticas de violencia física y cuestiona discursos que reducen simbólicamente a los sujetos (Didi-Huberman, 2014); 2) en relación con lo anterior, repite procedimientos que se mueven entre un libro y otro, un prólogo y otro, y dentro del prólogo mismo: el uso de una narradora en primera persona, elecciones léxicas y gramaticales, escenas de escritura, esquemas de exposición de la información, citas, paráfrasis y polisemias.
Palabras clave: violencia, estereotipo, escritura, Haití 


\title{
The Place of the Insistence: an Approach to the Allograph Prefaces of Edwidge Danticat
}

\begin{abstract}
In the following essay, I address a dimension of the Edwidge Danticat's work that has not been studied systematically: the configuration of her allograph prefaces. I am interested in approaching the introductions of The Butterfly's Way: Voices from the

Haitian Dyasporain the United States, Haiti Noir, Haiti Noir 2, understanding them as spaces of repetition. And, in this regard, I defend two central hypotheses: 1) through the prefaces, Danticat repeats an important topic that is visible in her first narrative works. I refer to the manifestations of precarious or vulnerable life in Haiti, that is to say, the ways in which a human being is exposed to others, under the forces of oppression or affect (Butler, 2006, 2010). From a critical position, the writer examines practices of physical violence, and questions discourses that reduce symbolically to social subjects (Didi-Huberman, 2014); 2) in relation to this, the author repeats narrative procedures that move between one book and the other, one preface and the other, and inside the preface: the use of first person narrator, grammatical and lexical elections, writing scenes, information exposure schemes, quotes, paraphrase and polysemy.
\end{abstract}

Keywords: violence, stereotype, writing, Haiti 


\section{Introducción}

En su Magnitud imaginaria (2013), el escritor Stanislav Lem prologa un libro de prólogos. Diversos, fascinantes, creativos, estos textos funcionan como entradas a obras inexistentes, a materiales culturales inventados. El gesto compositivo es revelador, porque ayuda a pensar en el ámbito de lo prologal como un territorio más complejo de lo que pareciera. En efecto, el propio Lem enumera algunas de las funciones que cumple este género de lo introductorio. Desde el principio, se refiere a su injusta categorización como elemento subsidiario, condenado a "la noria del trabajo servil" (p. 23). Su deseo, entonces, es liberarlo, articular el camino de una redención posible. Y, sin embargo, en palabras del polaco, el prólogo admite otros semblantes: "conoce, también, la soberbia y la agresión, el ademán inútil, el estruendo..." y las jerarquías (p. 24). El prólogo es protección ante las críticas, espacio del engaño, lugar de la palabra sobria (Lem, 2013). ${ }^{1}$

La reflexión de Lem puede habitar junto a la propuesta de Gerard Genette (2001), quien utiliza el vocablo prefacio para referirse "a toda especie de texto liminar (preliminar o pos-liminar) autoral o alógrafo, que constituye un discurso producido a propósito del texto que sigue o que precede" (p. 137). El crítico francés explora la versatilidad de las instancias prefaciales, a las que incluye en la categoría de "paratextos" o "umbrales". A la hora de definir y estudiar el fenómeno paratextual, Genette se interesa por "su emplazamiento (¿dónde?), su fecha de aparición (¿cuándo?), su modo de existencia, verbal o no (¿cómo?), las características de su instancia de comunicación, destinador y destinatario (¿de quién?, ¿a quién?) y las funciones que animan su mensaje (¿para qué?) (p. 10). ${ }^{2}$

Justamente, el crítico literario destaca una dimensión pragmática en estos umbrales discursivos (Genette, 2001). No solo se refiere a características como la "naturaleza del destinador, del destinatario, el grado de autoridad y responsabilidad del primero", sino a la interesante "fuerza ilocutoria" del "mensaje" paratextual (p. 13), que aloja un conjunto de funciones, tales como informar, mostrar "una intención", ofrecer "una interpretación", indicar un modo de leer e instaurar cierta promesa de veracidad (p. 15). ${ }^{3}$ En esta línea, Genette destaca la presencia de "elementos" de carácter "performativo" que tienen "el poder de cumplir aquello que describen" (p. 15). ${ }^{4}$ 
A nivel más específico, en lo que respecta a los prefacios de tipo alógrafo, es decir, aquellos que son escritos por una tercera persona distinta al creador del libro, Genette (2001) señala otras funciones importantes: la guía en el proceso de "lectura" (p.224), "la presentación” de aspectos genético-textuales o biográficos (p.225), la ubicación del "texto presentado en el conjunto de la obra de su autor" (pp.226-227), "la recomendación” (p.227), la "valoración”, el “comentario crítico" (p.229), la apuesta teórica, el desvío temático motivado por "una causa más vasta, o eventualmente diferente" (p.230), la expresión de una "molestia" (p.232) o la exhibición de una curiosa "hiperconciencia genérica" (p. 233).

Como se ve, el estudio de los paratextos introductorios supone la consideración de lo que estos dicen y hacen. Así, además de ofrecer una comprensión sobre la lengua, el abordaje sugerido permite entender las motivaciones emocionales e ideológicas que sustentan dichas composiciones.

\subsection{Propuesta}

En América Latina, es posible identificar prefacios que demuestran, ciertamente, la variedad constitutiva del género en cuestión. Ejemplo de ello son los numerosos umbrales de Macedonio Fernández en Museo de la Novela de la Eterna (1967), que superan las cien páginas, o los prólogos alógrafos de Jorge Luis Borges ${ }^{5}$, en los que se advierten, de acuerdo con Lafon (1999), procedimientos intertextuales y metatextuales, así como formas de lo repetitivo y lo novedoso.

Sin lugar a dudas, los prefacios referidos ocupan un lugar relevante en la historiografía literaria. Pero también es cierto que existen autores(as) contemporáneos(as) que ayudan a seguir pensando las dinámicas de elaboración paratextual.

En este trabajo, intento analizar la manera en la que operan tres prólogos alógrafos escritos por la haitiana-norteamericana Edwidge Danticat. ${ }^{6}$ Me interesa aproximarme a las introducciones de The Butterfly's Way: Voices from the Haitian Dyaspora in the United States, Haiti Noir, Haiti Noir 2, entendiéndolas como espacios de la repetición. Y, en este sentido, defiendo dos hipótesis centrales: 
a) a través de estos paratextos, Danticat reitera un tópico fundamental caro a sus primeras producciones narrativas: las manifestaciones de la vida precaria o vulnerable en Haití, es decir, los niveles de exposición de un ser humano frente a otro, bajo un amplio de arco de prácticas, donde caben las fisonomías de la opresión y el afecto (Butler, 2006; 2010). Ciertamente, Danticat se ocupa de históricas violencias padecidas por los sujetos sociales, lo que incluye un examen de situaciones de agresión física y una exploración de los discursos que "sobreexponen" o reducen simbólicamente a las poblaciones (Didi-Huberman, 2014).

b) en estrecho vínculo con lo anterior, Danticat repite procedimientos que transitan entre un libro y otro, un prólogo y otro, y en el interior del paratexto mismo: tipos de narrador, elecciones léxicas y gramaticales, escenas de escritura, esquemas de exposición de la información, citas, paráfrasis polisemias (Aiello, 2014; Bal, 1990; Genette, 1989; Pimentel, 2001; Aguiar, 1984; Cañelles et.al, 2002; Morales, 2017).

\subsection{Diálogos}

Al lado de estas aclaraciones, vale precisar un asunto de orden semántico y otro de carácter investigativo. Por una parte, el término repetición -sin duda, figura protagónica de este ensayo- hará referencia a la idea de copia, pero también acogerá la imagen de la alteración o el desvío.

La teoría musical ofrece, a este respecto, una serie de matices semánticos. De acuerdo con Alicia Rodríguez (2015), el concepto admite cuatro modalidades, a saber: "la repetición", "la secuencia", "la variación” y "el desarrollo" (p.145). Mi propósito no es usar esta clasificación para construir un juego de equivalencias; lo que busco es asumir dicha teoría como régimen metafórico que problematiza -sin negarlo- el nexo entre lo repetitivo y lo idéntico.

Además del discurso musical, cabe destacar aproximaciones que me han permitido atender y examinar el tópico de la reiteración. Una de ellas es la propuesta de Mary Gallagher (2010), quien analiza los nexos formales y temáticos entre la obra ficcional The Dew Breaker, de Edwidge Danticat, y otras de sus producciones 
narrativas, tales como The Farming of Bones, Breath, Eyes, Memory o Brother I'm dying. A su vez, Gallagher propone la expresión aesthetic of reverberation (p. 157), para sugerir la reaparición de tópicos y personajes dentro del universo planteado por el primer libro.

Igual de útil me ha resultado la obra de Antonio Benítez Rojo (1989), quien se propuso estudiar el Caribe como isla que se repite. Este pensador no sólo quiso subrayar las semejanzas socio-culturales entre los territorios antillanos, sino que adhirió a una curiosa paradoja sugerida por la Teoría del Caos: "toda repetición es una práctica que entraña necesariamente una diferencia..." (p.17). Finalmente, me he inspirado en un título de Florencia Bonfiglio (2014), quien analiza el "ensayo que se repite" en las producciones teóricas de Antonio Benítez Rojo, Édouard Glissant y Kamau Brathwaite; esto es, la presencia de un “discurso (común) antillano”, que traza "continuidades" con "la tradición anticolonialista caribeña y el espíritu colectivista, revolucionario, de los años 1960/1970 (...)" (p.1). ${ }^{7}$

Por otra parte, es importante señalar que, aunque existen trabajos críticos que abordan la literatura del Caribe desde el tópico de la vulnerabilidad, ${ }^{8}$ y propuestas que discurren sobre el modo en que Danticat representa a sujetos históricamente oprimidos ${ }^{9}$, mi lectura aporta algunas diferencias propositivas:

a. Si bien analiza un tema ampliamente estudiado por la crítica (la presencia y potencia de lo violento), lo hace desde en un universo textual muy especial, que no sido explorado de forma sistemática hasta ahora: los prólogos alógrafos. Tras este gesto de recorte y recontextualización, produce conocimiento novedoso en el ámbito de la crítica danticatiana, pues permite entender de qué otros modos la escritora "repite" (calca, matiza, renueva) el eje de la precariedad.

b. Sugiere nexos posibles entre los discursos prefaciales y las obras literarias, considerando especialmente las continuidades.

c. Instala un horizonte investigativo a partir del cual pueden examinarse los otros paratextos alógrafos elaborados por la autora caribeña.

d. Reflexiona alrededor de procedimientos narrativos empleados en estos discursos. 
e. Contribuye a la reflexión sobre el tópico del estereotipo en la producción danticatiana de carácter no ficcional.

f. Indaga en la figura de la narradora-lectora, de tal manera que ayuda a comprender la fisonomía de la autora caribeña como sujeto intelectual. ${ }^{10}$

\section{The Butterfly's Way...}

La visión dramática de la vida precaria, punto medular de la literatura de Danticat, re-aparece de diferentes maneras en el prólogo de The Butterfly's Way: Voices from the Haitian Dyaspora in the United States (2001). Desde el principio, la autora introduce el estruendo de un episodio funesto a través de recursos distintos: instala una escena de escritura, usa la primera persona narrativa, elige adjetivos y adverbios que le permiten expresar la emoción: "I have the extremely painful task of beginning this introduction on the same day that one of Haiti's most famous citizens, the radio journalist Jean Dominique, was assassinated" (p.9). ${ }^{11}$

Como se ve, la representación de la existencia vulnerable es indisociable de cierta "figuración autoral" (Luppi, 2010). ${ }^{12}$ Mientras se refiere al homicidio de Dominique, Danticat explicita fragmentos de su vida íntima: "I woke up this morning to a series of increasingly alarming phone calls, the first simply mentioning a rumor..." (Danticat, 2001, p. 9). ${ }^{13}$ Del mismo modo, informa sobre su actividad profesional: "The following hours...I went to teach my classes at the University of Miami” (p. 9). ${ }^{14}$ La auto-referencia, sin embargo, no le resta importancia al suceso, sino que le confiere veracidad. ${ }^{15}$ De hecho, el relato de la noticia destaca - desde el comienzo - la represión, la débil consistencia de las libertades, la degradación de la vida por parte del otro, la atroz distribución de las balas en el cuerpo: "The next few calls declared for certain that Jean had been shot: seven bullets in the head, neck, and chest" (p. 9). ${ }^{16}$ 
Como parte de esta preocupación por la violencia y la vulnerabilidad, la autora menciona el exilio que sufrió Jean Dominique. Y, justo aquí, vale detenerse en una acotación. Aunque el periodista no ha sido mencionado en las obras ficcionales que anteceden a este prólogo (Palabras, ojos, memoria, ¿Cric?;Crac! y Cosecha de huesos), es abordado desde ejes temáticos que están presentes en dichas producciones narrativas. En este sentido, lo que se repite acontece bajo el modo de una alteración, de un particularismo. Se reiteran los temas (cuerpos haitianos vulnerables), pero cambian las víctimas. ${ }^{17}$

Adicionalmente, mientras recuerda a Dominique y su trabajo como periodista, Danticat (2001) repite un tópico que atraviesa las obras señaladas. Me refiero a los estragos socio-afectivos producidos por el régimen duvalierista. A través del recurso de la descripción, la autora devela el contenido de un material fílmico. Para ser más específico, detalla la escena en la que una mujer aparece con el hombro herido, porque fue atacada a machetazos por los tonton macoutes (paramilitares de la dictadura): "During the taping, Jean squirmed in his seat, while Phil Donahue held up the stubbed elbow of Arlete Belance" (pp. 11-12). ${ }^{18}$

De este modo, la escritora no solo ratifica esa marcada inquietud por la exposición general de los haitianos, sino que reitera una voluntad de representar la relación más específica entre dictadura y sujeto femenino, permanente en sus relatos ficcionales. Ahora bien, tal como sucedía con el ejemplo del periodista, el caso de Arlete se constituye en una novedad (un ejemplo singular) entre los linderos de la recurrencia temática.

El tema de la movilización, que también aparece en las obras literarias mencionadas, es analizado en el estrecho margen prefacial. La autora recuerda el exilio que sufrieron los cineastas haitianos como consecuencia del régimen duvalierista, y el que padeció el propio Dominique durante la ola de violencia que siguió a la expulsión del presidente Jean Aristide. ${ }^{19}$ 
Sin embargo, la reflexión sobre los procesos migratorios (voluntarios o no) alcanza mayor profundidad narrativa cuando Danticat (2001) aborda la palabra dyaspora. En principio, introduce una frase nominal que veremos en otros umbrales textuales: "the tenth department" (p.14). ${ }^{20}$ Se trata de uno de los nombres para referirse a un Haití que "has nine geographic departments and the tenth was the floating homeland, the ideological one, which joined all Haitians living in the dyaspora" (p.14). ${ }^{21}$ La reflexión en torno a la diáspora remitirá, de un modo u otro, al universo de lo precario, de lo vulnerable: habitar/pertenecer al "décimo departamento" implicará diversas modalidades de agresión.

Para pensar el fenómeno diaspórico, Danticat (2001) se vale de la cita y paráfrasis de fuentes académicas: "I meant to borrow a phrase from a speech given by Gerard Alphonse Férère, $\mathrm{Ph} . \mathrm{D}$... in which he describes diasporaldyaspora as a term 'employed to refer to any dispersal of people to foreign soils."'(p. 14). ${ }^{22} \operatorname{Sin}$ embargo, la autora recorta otro fragmento de la fuente, con el fin de destacar un matiz: "But in our context used 'to identify the hundreds of thousands of Haitians living in many countries of the world"' (p. 14). ${ }^{23}$ Danticat selecciona, subraya oraciones e introduce un concepto que ayuda a describir los procesos migratorios. De una u otra manera, el prólogo se convierte en espacio de exhibición de las destrezas cognitivas y pedagógicas de la prologuista. Los prólogos de Danticat son espacios idóneos que le permiten, fundamentalmente, repetirse a sí misma, en tanto sujeto autoral.

Al mismo tiempo, la autora recurre a la enumeración de situaciones personales, con el objeto de destacar diferentes acepciones del término dyaspora. Esta última operación, que consiste en la exploración polisémica de una palabra específica, podrá advertirse también en los prólogos siguientes. Gracias a este recorrido semántico, el lector aprende varias cosas.

En primer lugar, que el vocablo diáspora es usado para señalar la ignorancia del interlocutor. El fenómeno es ilustrado a partir de la experiencia personal y tramitado narrativamente desde la primera persona: "being called 'Dyaspora' when expressing an opposing political point of view in discussions with friends and family members living in Haiti, who knew that they could easily silence me by saying, 'What do you know? You're a Dyaspora'” (Danticat, 2001, p. 14). ${ }^{24}$ En segundo lugar, el lector aprende que la palabra traza una reprobación moral: 
la narradora "recall conversations or debates ... where members of the dyaspora would be classified — justified or not — as arrogant, insensitive, overbearing, and pretentious people who were eager to reap the benefits of good jobs and political positions in times of stability..." (p. 15). ${ }^{25}$

Finalmente, el lector entiende que el término dispara los sismos de la culpa: "I would bow my head and accept these judgments when they were expressed, feeling guilty for my own physical distance from a country I had left at the age of twelve years during a dictatorship..." (p. 15). ${ }^{26}$

\subsection{Otras Amenazas}

En lo que concierne al gran tópico de la violencia, Danticat no solo aborda las prácticas de agresión verbal y corporal realizadas por militares y ciudadanos dentro de Haití. Como mencioné al principio, también se ocupa de la imagen del pueblo haitiano que ha sido construida por sujetos extranjeros. La autora se detiene en eso que Didi-Huberman (2014, p. 14) llama “sobreexposición”: cierto tipo de representaciones que espectacularizan o estereotipan al otro, y amenazan la existencia simbólica y real de los pueblos.

Ahora bien, según el pensador francés, el fenómeno puede contrarrestarse cuando se reconoce al otro en tanto sujeto "semejante" y "hablante", aun cuando nos resulte un “extraño" (2014, pp. 13-14). ${ }^{27}$

Este gesto de crítica y reconocimiento es efectuado de diversas maneras en los territorios prefaciales. Aquí en The Butterfly's Way..., por ejemplo, la escritora fustiga la fuerza esencializante del "estereotipo" y realza la creatividad haitiana (Bhabha, 1994). En este ejercicio dual, propone una dignificación de los sujetos sociales, al tiempo que muestra las fisuras en los modos de conocer la alteridad (Benjamin, 2002; Reyes Mate, 1991; Morales, 2017). El procedimiento consiste en citar las palabras de Dany Laferrière y Joel Dreyfuss (dos de los escritores compilados). Si del primer escritor toma la expression "America, We are here", como gesto afirmativo de toda una cultura, del segundo selecciona oraciones que subrayan la heterogeneidad: "we are not, as Joel Dreyfuss reminds the world in his essay, 'A Cage of Words', just people from 'the Poorest Nation in the Western 
Hemisphere,' but also people who 'have produced great art like that of Ireland and Portugal'..."28 El discurso de Dreyfuss también toma como referencia a países latinoamericanos: "'great writers and scholars like those of Russia and Brazil."” (Danticat, 2001, p. 16). ${ }^{29}$ Sin desatender el exceso dramático de Haití, la autora focaliza en sus fortunas. De lo que se trata, entonces, es de reconstruir una complejidad que ha sido epistemológicamente cercenada.

\section{Haiti Noir}

Danticat edita y prologa una compilación de relatos de género negro (policial), escritos por haitianos que habitan en la isla o en la diáspora: Haiti Noir (2011). ${ }^{30}$ Desde el comienzo del texto, la repetición ostenta su ímpetu: la semejanza formal y temática con respecto al prólogo de Butterfly ways... es indiscutible. Precisamente, en las primeras líneas, recurre a una estructura que podría resumirse de la siguiente manera: escena de escritura narrada en primera persona, seguida de la referencia a una anécdota funesta que ocurre de forma paralela al acto de escribir: "I began working on this anthology about a year before January 12, 2010, when Haiti was struck by its worst natural disaster in over two hundred years" (p.11). ${ }^{31}$ Como si fuera poco, el proceso de escritura en tiempo presente recuerda la persistencia del drama social: "As I am writing these words, survivors remain huddled by the thousands in displacement camps..." (p.11). ${ }^{32}$ Por otro lado, si en el prólogo de The Butterfly's Way... Danticat efectuaba un ejercicio de variaciones semánticas sobre la palabra Dyaspora, en este realiza una exploración polisémica del término Noir. De manera que el lector puede observar una suerte de operación productiva (eficiente, generadora de discurso) que retorna. Al lado de ella, se advierten los recursos de la cita y la paráfrasis de fuentes académicas, también utilizados en el prólogo anterior. "Noir of course meansamong other things - black, and Haiti became the first black republic in the Western Hemisphere ... Noir ... as the scholar Jana Evans Braziel points out ... also refers to

any Haitian citizen, regardless of race" (pp.11-12). ${ }^{33}$ La autora construye umbrales que, aunque pueden ser leídos de manera individual, operan como entidades porosas, permeables. En algunos casos, practica un leve reciclaje escritural que pone en evidencia cierta relación entre retorno y novedad (Lafon, 1999). Sin embargo, en otros casos puntuales, ofrece una copia idéntica, una oración exacta. Por eso, debe hablarse aquí de niveles o grados de la repetición (como señalaba la teoría musical). 
Justamente, un ejemplo de reiteración exacta es la frase "tenth department". Mientras alude a los escritores convocados, Danticat (2011) asevera: "Migration is such an integral part of the Haitian experience that those living outside of the country were once designated as part of a 'tenth department,' an ideological auxiliary to Haiti's first geographical nine" (p. 14). ${ }^{34}$ Como puede verse, el prólogo revela una relación léxica y temática con el prefacio anterior. No solo porque la autora reutiliza segmentos sintácticos, sino porque el fragmento propone una reflexión sobre los modos en los que se constituyen las identidades (adentro y afuera del suelo nacional).

\subsection{Fijezas}

En este prólogo, Danticat vuelve a analizar la violencia que se genera a partir de los discursos estereotipantes. Tal como lo hizo en el prefacio anterior, la autora exhibe y ataca visiones que esencializan. Recurre otra vez a la cita, a la paráfrasis, al contraste entre fuentes bibliográficas, a la indagación en tradiciones de pensamiento. Se repiten algunos procedimientos, pero varían los ejemplos, o al menos hasta cierto punto. Esta vez cuestiona las historias zombies creadas por los militares de la invasión estadounidense entre 1915 y 1934 (Danticat, 2011), en las que el sujeto haitiano es representado como una entidad cercana al mundo natural $y$, en consecuencia, al reino de lo animal o a la esfera de lo menos humano (Giorgi, 2014). La autora se refiere a libros "such as Captain John Houston Craige's Black Bagdad and Cannibal Cousins, along with William Seabrook's The Magic Island and Richard Loederer's Voodoo Fire in Haiti, shrouded Haiti in a kind of mystery that aimed to stereotype and dehumanize its people" (2011, p. 12). ${ }^{35}$

Danticat cita un fragmento del libro de Loderer y enseña la anatomía ideológica de un discurso militar plagado de tensiones, en cuyo seno se alberga la paradoja de una pretendida exaltación que es, sobre todo, condena, humillación: 
"The black race is far closer to the earth than the white, and for that reason they are happier than all the white men put together. A negro believes without asking why; he submits to nature" (p.12). ${ }^{36}$ No obstante, como si se tratara de una vuelta de tuerca, Danticat resume la idea que Jean Price-Mars (1928), un intelectual haitiano, trató de fomentar en sus colegas: "Haiti's own stories were worth telling" (Danticat, 2011, p. 13). ${ }^{37}$

Desde laperspectiva de Price Mars, no se trataría de legitimar la animalización, sino de reivindicar la singularidad, el paisaje propio, la riqueza cultural. Usando la paráfrasis, la autora recordará las exhortaciones del famoso pensador: "Forget trying to rewrite the great works of French literature on which you had been raised, he exhorted the Haitian writers of his time. Turn to Haitian life and history and folklore and find your inspiration there" (2011, p. 13). ${ }^{38}$ Tras esta referencia académica, la autora traza un mapa de los escritores que siguieron la consigna: "Ida Salomon Faubert", "Jacques Roumain", "Jacques Stephen Alexis", "Philippe Thoby-Marcelin" y "Marie VieuxChauvet" (pp.13-14). En tal sentido, Danticat utiliza el prólogo para repensar la tradición literaria como un cruce de apuestas estéticas, epistémicas y políticas.

La idea de la riqueza cultural se convierte en un dispositivo que permite edificar una imagen renovada del propio Haití. Danticat insiste en esta tesis en diferentes segmentos del prefacio. Me interesa analizar dos casos adicionales. Aunque el primero de ellos se encuentra al principio del prólogo, posee una fuerte cercanía temática con el párrafo anterior, en tanto subraya que la esfera estética construye una visión integral, no reduccionista, del pueblo haitiano: "Whether expressed in vibrant and colorful paintings ... or the poignant, humorous, erotic, lyrical (and yes, also dark) short stories and novels of its writers, Haiti's more nuanced and complex face often comes across in its arts" $\left(2011\right.$, p. 11). ${ }^{39}$

En el segundo caso, casi al final del prefacio, Danticat repite la expresión "more nuanced and complex": "Each story is of course its own single treasure, but together they create a nuanced and complex view of Haiti and many of its neighborhoods and people" (p.15) ${ }^{40}$. ¿Olvido, deliberada recurrencia, automatismo? A mi juicio, se trata de una preocupación temática que se torna fórmula. El prólogo, entidad irreductible, aparece también como el espacio en el que se evidencian las cristalizaciones o desgastes retóricos. 


\section{Haiti Noir 2}

En el año 2013, se publica una segunda parte de Haiti Noir. La editora y prologuista es nuevamente la escritora caribeña, quien repite alguno de los temas y procedimientos examinados hasta el momento. Desde el comienzo, el tópico de la vulnerabilidad se hace evidente con la alusión a los crímenes cometidos en territorio haitiano. Si hay una imagen persistente en estas líneas, tiene que ver con la exposición humana a la injusticia, a la irregularidad de un sistema penal que no es eficaz; para decirlo de otro modo, la exposición humana a instituciones enfermas, deterioradas en su filosofía, en su osamenta moral.

El prólogo es usado para reflexionar sobre las dimensiones dramáticas de lo real y para pensar en las relaciones entre ficción y contexto social. Por un lado, y según Danticat, el entorno estimula el género Noir; por el otro, la literatura corrige la impunidad que impera en la nación caribeña: "Which makes the noir genre rather redemptive in Haiti. At least justice can be found in our writers' imaginations. At least justice can be found in art." (2013, parr. 10). ${ }^{41}$ Como en los otros prólogos, Danticat recurre al saber libresco para construir su propuesta argumentativa.

En este caso, parafrasea una idea del escritor haitiano Jacques Roumain, que condensa todo lo expresado previamente: "sometimes art creeps into life and sometimes life creeps into art." (parr. 10). ${ }^{42}$

Tal como lo hizo en los dos prólogos analizados, la autora vuelve sobre la problemática de las representaciones que amenazan simbólicamente al pueblo haitiano (Didi-Huberman, 2014). Para combatir tales simplificaciones, exalta la diversidad y el poder creativo del país de origen. La instancia prefacial opera una y otra vez como terreno de lo político. A este respecto, la autora usa "la función conativa" (Jakobson, 1981, p. 355), para dirigir una invitación intelectual al lector: "So for every writer here you should seek out at least ten more, noir or otherwise, in the cannon of Haitian literature". En efecto, Danticat acompaña estas oraciones con un emotivo comentario sobre la producción estética local: "This is especially important for a country that is unfairly known more for its natural and political disasters than its exciting and vibrant literature" (2013, parr. 5). ${ }^{43}$ 
Ahora bien, en este punto, Danticat tiene que enfrentar una curiosa paradoja: si la tesis del talento estético ayuda a rebatir estereotipos, también es cierto que los relatos de los autores compilados son capaces de reforzar tales preconcepciones, en la medida en que narran historias dramáticas: "After the first Haiti Noir was published, people kept asking if I wasn't contributing to a negative image of the country by editing a book filled with so many 'dark' stories about Haiti” (2013, parr. 6). ${ }^{44}$

Esta paradoja es sorteada con la idea de la complejidad, que permite confrontar toda clase de simplificaciones: "showing the brilliance of our writers and their ability to address Haiti's difficulties through their art can only contribute to a more nuanced and complex presentation of Haitian lives" (parr. 6). ${ }^{45}$ Sin embargo, a través de esta cita puede apreciarse también el retorno de la ecuación retórica, es decir, la repetición exacta de ese fragmento que apareció dos veces en el prólogo anterior: "more nuanced and complex presentation of Haitian lives".

Aun así, la instancia prefacial de Haiti noir 2 encarna otras formas de la repetición. Por un lado, este paratexto alógrafo es el espacio en el que reaparece el resumen, el laconismo reseñístico (la autora evita profundizar en el contenido de los relatos compilados, para no restarles protagonismo). Por otro lado, el prefacio es el albergue textual en el que se retoman las representaciones del haitiano diaspórico. Justamente, en el último párrafo, Danticat imagina una fiesta a la que asisten los escritores compilados: "While some konpa or rasin music and even some blues is playing in the background, I am still bringing out the salt cod-filled chiktay and the Barbancourt rum, and putting the finishing touches on my welcoming address" (parr. 13). ${ }^{46}$ En esta escena, la escritora se presenta desde una doble dimensión: norteamericana (residente de Estados Unidos y vinculada al blues) y antillana (ligada a una bebida, una comida y dos ritmos haitianos). Mediante este texto introductorio, Danticat confirma lo expresado en el plano de la entrevista. Allí se ha definido como "poligeográfica" y "ageográfica", 47 como una mujer que entraña la triple conjunción de lo americano, lo haitiano y lo africano (Munro, 2010; Mardorossian, 2010; Nana y Danquah, 2001). 


\section{Conclusiones}

Tal como se ha venido proponiendo, los prefacios de Danticat se constituyen en una oportunidad para pensar los límites y alcances de la escritura, no solo en términos de procedimientos retóricos, narrativos y pragmáticos, sino de apuestas políticas. En definitiva, su propuesta ratificaría eso que Genette (2001) dice sobre la operabilidad de los paratextos y, por extensión, de los prólogos mismos: "pueden perseguir varios fines a la vez" (p. 16).

En cuanto al uso de recursos formales y funciones, es prudente decir que, a través de la inscripción genérica, el uso de la primera persona y las explícitas remisiones autobiográficas, los prólogos de Danticat instalan un pacto de autenticidad. Funcionan como un albergue textual de la verdad, que podría enunciarse sintéticamente de la siguiente manera: lo que se cuenta aquí, lo he vivido, lo he visto, lo he leído, y, en consecuencia, puedo dar fe de ello, puedo probarlo.

Adicionalmente, estos prefacios comportan funciones de presentación y comentario crítico. Ahora bien, lo que más se destaca en ellos es que operan como escenarios de ampliación reflexiva y temática, pues son usados para explorar las formas de la subjetividad y el vínculo con los otros.

Justamente, en lo que atañe a la dimensión ético-política, los prólogos examinados develan un claro interés por los nexos entre discursos y violencias, entre escritura y articulación de los imaginarios. En esta misma dimensión, los prólogos actualizan dos pulsiones que signan gran parte de la obra de Danticat: a) la necesidad de fomentar una "compasión" posible en el lector (Reyes Mate, 1991) a partir de la "saturación dramática", esto es, la acumulación narrativa de relatos nefastos (Morales, 2017); b) el intento de construir una "memoria", que implica la dignificación de los oprimidos (Benjamin, 2002, citado en Morales, 2017) ${ }^{48}$

En este sentido, considero que los prólogos de Danticat adquieren una incontestable actualidad, si se admite que el racismo, la xenofobia y la violencia estatal asumen permanentes inflexiones. La elección de este corpus textual está mediada, entonces, por el deseo de potenciar una reflexión sobre la vida contemporánea, en términos de la defensa o borradura de los derechos humanos (2017). 


\section{Notas}

${ }^{1}$ Para una reflexión sobre el tema, véase Schvartzman (2016).

2 Usaremos "prefacio" y "prólogo" como términos intercambiables. Por lo demás, conviene decir que los términos ubicados en los paréntesis se encuentran en cursiva en el original.

${ }^{3}$ La cursiva aparece en el original.

${ }^{4}$ La cursiva aparece en el original.

${ }^{5}$ Una reseña elaborada por la editorial Impedimenta recuerda el acierto de Roberto Valencia, prologuista de Lem, quien reconoce el legado de Borges y Rabelais en el proyecto del polaco. El texto propone, además, un vínculo con obras como “Tlön, Uqbar, Orbis Tertius", así como con "Funes, el memorioso"(véase sección de bibliografía).

${ }^{6}$ El prólogo alógrafo es aquel que no está construido por el autor(a) del libro, sino por una tercera persona (Genette, 2001; Pont, 2012).

${ }^{7}$ En cursiva en el original.

8 Ver a este respecto las propuestas de Stecher (2011), De Ferrari (2007), Vidal (2013) y Knepper (2012). La agrupación de estas fuentes bajo un mismo signo no debe entenderse como un intento de homogeneización. Para ser justo, habrá que decir que comparten semejanzas y diferencias entre sí, en lo que concierne a sus articulaciones teóricas-críticas y objetos de estudio. Por citar un ejemplo, los tres primeros trabajos abordan autores(as) distintos a Danticat; el último, analiza Brother I'm dying, de la escritora en cuestión.

${ }^{9}$ En este punto adhiero a y coincido con los trabajos de Daroqui (2005), Chancy (2010), Gardaretti (2011), Knepper (2012), Munro (2010), Maeseneer (2006), Pulitano (2008), Stecher y Oliva (2011). 
${ }^{10}$ Danticat no solo ha construido preámbulos de compilaciones narrativas, sino de novelas y libros de investigación social.

11 “Tengo la tarea extremadamente dolorosa de comenzar esta introducción el mismo día en el que uno de los ciudadanos más famosos de Haití, el periodista Jean Dominique, fue asesinado." Todas las traducciones al español son mías. La paginación del original está basada en números romanos.

${ }^{12}$ El crítico Juan Pablo Luppi (2010) parte de la noción de "mitologías autorales", propuesta por Julio Premat (2006), para analizar la "construcción social e imaginaria del autor" (Luppi, 2010) Rodolfo Fogwill en diversas elaboraciones paratextuales. El ensayo de Luppi me ha servido de guía para identificar procesos de figuración en Danticat.

13 "Me levanté en la mañana con una serie de llamadas cada vez más alarmantes, la primera simplemente mencionaba un rumor".

14 "En las siguientes horas, fui a dictar clases a la Universidad de Miami”.

15 Cuando Genette caracteriza a la instancia prefacial, señala algunas de sus configuraciones formales. Desde su perspectiva, el prefacio puede adoptar "la apariencia del 'modo narrativo', por ejemplo, para hacer el relato verídico o no de las circunstancias de la redacción [...] o del descubrimiento del texto, cuando es atribuido a un autor ficticio". Además, puede asumir "la forma dramática de un diálogo", "de una pequeña pieza de teatro", e, inclusive, la forma de un poema (145).

16 "Las escasas llamadas siguientes confirmaron que a Jean le habían disparado: siete balas en la cabeza, cuello y pecho".

${ }^{17}$ Para una reflexión filosófica sobre la vida precaria en clave de Butler, véase Mattio (2010).

18 “Durante la grabación, Jean se retorcía en su silla, mientras Phil Donahue sostenía el hombro apuñalado de Arlete Belance".

${ }^{19}$ Para una descripción detallada de la expulsión de Aristide, véase Danticat (2007). 
20 "El décimo departamento".

21 “tiene nueve departamentos geográficos y el décimo era un hogar flotante, el ideológico, que unía a todos los haitianos de la diáspora”.

22 "Quiero tomar prestada la frase de un discurso ofrecido por Gerard Alphonse Férère, Ph.D ... en el que describe diaspora/dyaspora como un término 'empleado para referirse a cualquier tipo de gente dispersa en suelos extranjeros"”.

23 "Pero en nuestro contexto es usado para 'identificar a los cientos de miles de haitianos que viven en muchos países del mundo".

24 “ser llamada Dyaspora al expresar una perspectiva política opuesta, en discusiones con amigos y familiares residentes en Haití, quienes sabían que podían silenciarme fácilmente diciéndome “¿Qué sabes tú? Eres una Diáspora””.

25 "recordar conversaciones o debates ... donde miembros de la diáspora eran clasificados - justificadamente o no - como gente arrogante, insensible, autoritaria y pretenciosa, con ganas de recoger los beneficios de buenos trabajos y posiciones políticas en tiempos de estabilidad". La cursiva es del original.

26 "Yo inclinaría la cabeza y aceptaría estos juicios cada vez que fueran expresados, sintiendo culpa por mi distancia física con un país que dejé a los doce años, durante una dictadura..."

${ }^{27} \mathrm{El}$ autor sustenta la idea de reconocimiento en postulados de Bataille y Blanchot.

${ }^{28}$ En este caso, los tres puntos suspensivos pertenecen a la cita original.

29 “América, aquí estamos", "no somos, como Joel Dreyfuss recuerda en su ensayo, 'Una jaula de palabras', únicamente los de 'la nación más pobre del hemisferio occidental', también somos el tipo de gente que 'ha producido un gran arte como Irlanda o Portugal"”, "“grandes escritores como Rusia y Brasil"”.

${ }^{30}$ Curiosamente, la autora incluye un cuento propio, tanto en Haiti Noir como en Haiti Noir 2. 
31 “Comencé a trabajar en esta antología hace un año aproximadamente, antes del 12 de enero de 2010, cuando Haití fue golpeado por el peor desastre natural de los últimos doscientos años".

32 "Mientras escribo estas palabras, miles de sobrevivientes permanecen apiñados en campos de desplazamiento".

33 "Noir por supuesto significa — entre otras cosas - negro, y la gente de Haití se convirtió en la primera república negra en el hemisferio occidental ... Noir ... como subraya la académica Jana Evans Braziel ... también se refiere a cualquier ciudadano haitiano, independientemente de su raza".

34 “décimo departamento", "la migración es una parte tan integral de la experiencia haitiana que, esos que viven fuera del país, fueron designados alguna vez como parte de un "décimo departamento", un auxiliar ideológico de los primeros nueve departamentos geográficos de Haití”.

35 “como el Black Bagdad y Cannibal Cousins, del Capitán John Houston, junto con The Magic Island, de William Seabrook, y Voodoo Fire in Haiti, de Richard Loederer, envolvieron a Haití en una suerte de misterio que logró estereotipar y deshumanizar a su gente".

${ }^{36}$ La cursiva es del original. "La raza negra está mucho más cerca de la tierra que la blanca, y por esta razón los negros son más felices que todos los blancos juntos. Un negro cree sin preguntar el porqué; él se somete a la naturaleza”.

37 "Las propias historias de Haití merecen contarse."

38 "Olvídense de reescribir esas grandes obras de la literatura francesa con las que han crecido, él exhortaba a los escritores de su época. Giren hacia la vida, la historia y el folclor haitiano, y encuentren allí su inspiración”.

39 "Sea expresado en vibrantes y coloridas pinturas ... o a través de los conmovedores, humorísticos, eróticos, líricos (y sí, también oscuros) cuentos y novelas, la cara más matizada y compleja de Haití proviene de sus artes". 
40 “Cada historia es, por supuesto, un tesoro en sí misma, pero todas las historias juntas crean una visión matizada y compleja de Haití, de sus habitantes y sus barrios".

41 "Lo cual hace al género negro más que redentor en Haití. Al menos la justicia se cumple en la imaginación de nuestros escritores. Al menos la justicia puede ser hallada en el arte".

${ }^{42}$ Las citas del prólogo son tomadas de una versión digital (en formato de libro electrónico), cuya diagramación carece de paginación. En este sentido, he seguido la recomendación del Manual APA resumido por la Universidad Javeriana de Cali, Colombia, donde se sugiere el uso de la abreviatura "parr" (párrafo) ante casos de esta naturaleza. "A veces el arte se desliza en la vida y, a veces, la vida se desliza en el arte".

43 "Por cada escritor aquí presente, deberías buscar al menos diez más, sean de género negro o no, en el canon de la literatura haitiana. Esto es especialmente importante para un país que, injustamente, es más conocido por sus desastres naturales y políticos que por su emocionante y vibrante literatura”.

44 "Después de que el primer Haiti Noir fuese publicado, la gente me preguntaba si, al editar un libro lleno de historias tan 'oscuras', no estaba produciendo una imagen negativa del país".

45 "mostrar el brillo de nuestros escritores y su habilidad para abordar, a través de su arte, las dificultades de Haití, solo puede contribuir a una presentación más compleja y matizada de las vidas haitianas".

46 "Mientras suena en el fondo alguna música tipo kompa o rasin e, incluso, un blues, aún estoy llevando el filete de bacalao salado tipo chitkay y el ron Barbancourt, y dándole los toques finales a mi discurso de bienvenida". A propósito de esta cita, vale la pena efectuar tres recomendaciones. En primer lugar, para indagar sobre el género "Kompa" (nótese que la palabra de la cita de Danticat está en creol), véase la página: http://www.afropedea.org/compa-kompa-music. En segundo lugar, en lo que respecta al género "Rasin", sugiero la web: http://www.haitianmusic. net/popular - haitian — music/rasin. Finalmente, a la hora de explorar la cocina haitiana, aconsejo visitar el portal "kreyolcuisine", que brinda una descripción del 
47 “Ageographic", "poligeographic". Para indagar en esta expresión concreta, ver Mardorossian (2010) y Nana y Danquah (2001).

${ }^{48}$ He seguido la relación entre compasión y memoria propuesta por el filósofo español Manuel Reyes Mate, notable estudioso de la obra de Walter Benjamin.

\section{Referencias}

Afropedea.(s.f). Kompa. http://www.afropedea.org/compa-kompa-music

Aguiar e Silva, V. (1984). Teoría de la literatura. Madrid: Gredos.

Aiello, F. (2014) "Moi, Tituba de Maryse Condé: reescribir la literatura de los hombres", CELEHIS, 28, pp. 11-29. Recuperado de http:/www.scielo. org.ar/scielo.php?script=sci_arttext\&pid=S2313-94632014000200001

Bal, M. (1990). Teoría de la Narrativa, Barcelona, Cátedra.

Benjamin, W. (2002). "Sobre el concepto de historia", IX, La dialéctica en suspenso. Santiago de Chile: Lom.

Benítez Rojo, A. (1989) La isla que se repite. El Caribe y la perspectiva postmoderna. Hanover: Eds. del Norte.

Bhabha, H. (1994). El lugar de la cultura. Buenos Aires: Manantial

Bonfiglio. F. (2014). El ensayo que se repite o el Caribe como lugarcomún Antonio Benítez Rojo, Édouard Glissant, Kamau Brathwaite). (2014). Anclajes, vol.18, No.2. Recuperado de http://www.scielo.org.ar/ scielo.php?script $=$ sci_arttext\&pid=S1851-46692014000200002

Butler, J. (2006). Vida Precaria. El poder del duelo y la violencia. Buenos Aires: Paidós. . (2010). Marcos de guerra: las vidas lloradas. Barcelona: Paidós. 
Cañelles, R., Zapata, A., Ayuso, A., Cañelles, I., Lorenzo, A., Duel, M.J. (2002). Curso de teoría y práctica del relato, Estructura del relato y ejercicios de estilo. Madrid, Fuentetaja.

Chancy, M. (2010). "Violence, Nation, and Memory: Danticat's Farming of bones", en: Munro,

Martin (ed.), Edwidge Danticat. A reader's guide. Estados Unidos: University of Virginia Press.

Danticat, E. (2001). The Butterfly's Way. Voices from the Haitian Dyaspora in the United States. New York: Soho Press.

. (2011). Haiti Noir. New York: Akashic Books Noir Series

. (2013). Haiti Noir 2. New York: Akashic Books Noir Series.

. (2005). After the dance. A walk through carnival of Jacmel. Estados Unidos: Vintage. . (2007). Brother I'm dying. Estados Unidos: Alfred Knopf.

Daroqui, M. (2005). Escrituras heterofónicas. Narrativas caribeñas del siglo XX. Rosario: Beatriz Viterbo.

De Ferrari, G. (2007). Vulnerable states: bodies of memory in contemporary Caribbean fiction. United States: University of Virginia Press.

Didi-Huberman, G. (2014). "Parcelas de humanidades", Pueblos expuestos, pueblos figurantes. Buenos Aires: Manantial.

Editorial Impedimenta. (s.f). Magnitud imaginaria. Recuperado de http:// impedimenta.es/prensa.php/llmagnitud — imaginariagg — de — stanislawlem 
Fernández, Macedonio. (1967). Museo de la novela de la eterna. Buenos Aires: Centro Editor de América Latina.

Gallagher, M. (2010) “Concealment, Displacement, and Disconnection:

Danticat's The Dew Breaker", en Martin Munro (ed). Edwidge Danticat. A reader's guide. Estados Unidos: University of Virginia Press.

Gardaretti, C. (2011). “30,000 `Sebastien Onius` Brought from the Margins to the Center through Memory in Edwidge Danticat's The Farming of Bones". E-scrita. Revista do Curso de Letras da UNIABEU, 2, 6. Recuperado de http://revistauniabeu.edu.br/index.php/RE/article/view/217

Giorgi, Gabriel. (2014). Formas comunes. Animalidad, cultura, biopolitica. Buenos Aires: Eterna Cadencia.

Genette, G. (1989). Figuras III. Barcelona: Lumen.

Genette, G. (2001). Umbrales. México: Siglo XXI.

Haitian music. (s.f). Rasin. Recuperado de http://www.haitianmusic.net/ popular - haitian — music/rasin/Kreyolcuisiine. (S.f). Bacalao chiquetaille. Recuperado de http://es.kreyolcuisine.com/receta_criolla. asp?s=bacalao_chiquetaille

Knepper, W. (2012). In/justice and necro-natality in Edwidge Danticat's Brother, I'm Dying. The Journal of Commonwealth Literature. 47(2), pp. 191-205.

Jakobson, R. (1981). Ensayos de lingüistica general. Barcelona: Seix Barral.

Lem, S. (2013). Magnitud imaginaria. España: Impedimenta.

Lafon, M. (1999). Poética del prólogo. Boletín del Centro de Estudios de Teoría y Crítica Literaria. 
Luppi, J. (2010). 'Llamar la atención, soltar un aliento y escucharse'. Facetas del yo en la escritura paratextual de Fogwill. Actas del II Coloquio Internacional Escrituras del Yo. Recuperado de http://www.celarg.org/int/ arch_coloquios/luppi_acta.pdf

Maeseneer, R. de. (2006). Encuentro con la narrativa dominicana contemporánea, Madrid, Iberoamericana.

Mardorossian, C. (2010). "Danticat and Caribbean Women Writers", en Munro, M. (ed.). Danticat. A reader's guide, Estados Unidos, University of Virginia Press.

Mattio, E. (2010). Vulnerabilidad, normas de género y violencia estatal: ontología social y política sexual en la última Judith Butler. Pensamiento Plural, 7, pp.159-172. Recuperado de https://periodicos.ufpel.edu.br/ojs2/index. php/pensamentoplural/article/view/3650/2986

Morales, J. (2017). Variaciones sobre el recuerdo doloroso y el olvido en la obra de Edwidge Danticat. Tesis de maestría, Universidad de Buenos Aires, Facultad de Filosofía y Letras. Disponible en forma virtual en repositorio:http://repositorio.filo.uba.ar/handle/filodigital/3350

Munro, "Introduction: Borders", en Martin Munro (ed.).(2010). Edwidge Danticat. A reader's guide. Estados Unidos: University of Virginia Press.

Nana, M. y Danquah, A. (2001). On Becoming American; Personal Essays by First Generation Immigrant Women, New York, Hyperion.

Pimentel, L. (2001). El espacio en la ficción. Ficciones espaciales. La representación el espacio en los textos narrativos. Ciudad de México: Siglo Veintiuno Editores, UNAM

Pont, Jaume. (2012). Espejo y laberinto. Estudios sobre literatura hispánica contemporánea. Lérida: Editions de la Universitat de Lleida. 
Premat, J. (2006). "El autor. Orientación teórica y bibliográfica”, en Premat, Julio (ed.). Figures d'Auteur. Figuras de autor. Cahiers de LI.RI.CO. Littératures 14 contemporaines du Río de la Plata N. 1, pp. 311-317. Université de Paris 8 Vincennes - Saint-Denis.

Price-Mars, J. (1928). Ainsi parla l'oncle. Essai d'ethnographie. Compiègne: Imprimerie de Compiègne. Información bibliográfica tomada de la página http://ile-en-ile.org/price-mars/.

Pulitano, E. (2008). Landscape, Memory and Survival in the Fiction of Edwidge Danticat. Anthurium. A Caribbean Journal Studies, 6 (2). Recuperado de http://scholarlyrepository.miami.edu/cgi/ viewcontent.cgi? article $=1165 \&$ context $=$ anthurium

Reyes Mate, M. (1991). La razón de los vencidos. Barcelona: Antrophos. . (2006). Medianoche en la historia: comentarios a las tesis de Walter Benjamin "Sobre el concepto de historia." Madrid: Trotta.

Rodríguez, A. (2015). Música ESO I. Editex. Recuperado de www.google.book. com

Schvartzman, J. (2016). Límites y emancipación del prólogo. Programa de seminario de maestría/doctorado. Facultad de Filosofía y Letras de la Universidad de Buenos Aires (UBA).

Stecher, L y Oliva, M. (2011). "Subjetividades, raza y memoria en Cosecha de huesos, de Edwidge Danticat." Revista Casa de las Américas, No. 264.

Stecher, L. (2011). Diáspora, duelo y memoria en Mi hermano de Jamaica Kincaid. Revista Chilena de Literatura. No. 78, pp. 185-203. Recuperado de http://www.redalyc.org/pdf/3602/360233417009.pdf 
Universidad Javeriana. Manual Normas APA. Cali: Universidad Javeriana de Cali. Recuperado de http://portales.puj.edu.co/ftpcentroescritura/ Recursos\%20C.E/Estudiantes/Referencia\%20bibliogr\%C3\%A1ficas/ Normas\%20APA\%206a\%20actualizada.pdf http://es.kreyolcuisine.com/ receta_criolla.asp?s=bacalao-chiquetaille

Vidal, L. (2013). Cuerpos vulnerables con máscaras blancas. Yo, Tituba, la bruja negra de Salem, de Maryse Condé. Cuadernos de literatura del Caribe e Hispanoamérica. N.18, pp. 167-193. Recuperado de http://investigaciones. uniatlantico.edu.co/revistas/index.php/cuadernos_ literatura/article/view/1210

\section{Agradecimientos}

Quiero agradecer especialmente a Laureano Quant, cantante lírico, por sus asesorías conceptuales sobre la "variación musical" en tanto metáfora posible; a Elsa Noya, por estimular mi interés en las operaciones narrativas; a Mónica del Valle, por conducirme a pensar en la obra de Danticat desde nuevas aristas, y a vislumbrar la historia haitiana más allá del estereotipo funesto; a Julio Schvarztman, por sus lúcidos comentarios de orden estilístico y conceptual; a Adriana Amante, por su creativa visión del quehacer crítico; a Mónica Quant, por sus orientaciones con el idioma inglés; a Celina Carquez, por resaltar -hace unos años- la utilidad general del concepto de "representación"; a Jorge Dávila, por señalar la importancia del tópico de la rebeldía; a Carlos Fisgativa, porque su novedoso curso sobre Derrida, el cine y la fotografía me permitió imaginar nuevos recortes textuales y visuales para mi investigación; a Wilfredo Vega y Yudy Silva, por sus lecciones acerca del vínculo entre memoria, el arte y la escritura; a Edgardo Cuadrado, por todo su conocimiento lingüístico; a Oscar Arcos, por la suma de consejos académicos y el conjunto de enseñanzas en el área de la tematología; a Emiro Santos, por haber compartido muchos de sus saberes escriturales, y por ayudarme, junto a Silvana Arroyo y Henry Escobar, a meditar sobre el fenómeno de la relación compasiva, a partir de la importancia teórica de la corporalidad. Finalmente, agradezco a Nora Domínguez, Isabel Quintana y Simón Henao, por estimular reflexiones acerca de las figuraciones de los pueblos. 


\section{Fuentes de financiamiento}

El artículo se inscribe en dos marcos. Por un lado, fue construido como ensayo final en el contexto del seminario doctoral "Límites y emancipación del prólogo", dictado por Julio Scvharztman, en la Universidad de Buenos Aires. Por el otro, hace parte de mi tesis doctoral en curso, que es financiada por la beca Conicet.

La versión aquí presentada incluye el contenido del texto original. Sin embargo, contiene algunas adiciones, que corresponden a reajustes de estilo, incorporación de nuevos antecedentes bibliográficos y acotaciones sobre los aportes de esta propuesta interpretativa.

Vol. 9 (1), 2019 / EISSN: 2215 - $3934 \quad 29$ 